\title{
PRODUÇÃO DE SERRAPILHEIRA EM UM FRAGMENTO DE FLORESTA OMBRÓFILA MISTA COM SISTEMA DE FAXINAL
}

\author{
Production of litter in a fragment of the florets ombrofila mista \\ with faxinal sistem
}

Valdemir Antoneli, Dr. em Geografia, Prof. Adjunto UNICENTRO, Campus de Irati, PR vaantoneli@gmail.com

Edivaldo Lopes Thomaz

Dr. Em Geografia, Prof. Adjunto, UNICENTRO, Campus Guarapuava, PR Bolsista Produtividade em Pesquisa, CNPq, Brasil. edivaldo.thomaz@pq.cnpq.br

Artigo recebido em 16/03/2012 e aceito para publicação em 15/06/2012

RESUMO: O objetivo deste estudo, foi estimar a produção de serrapilheira, em um fragmento de Floresta Ombrófila Mista, associado ao Sistema de Faxinal, no município de Prudentópolis-PR e a influência dos animais na exposição do solo. As coletas, foram realizadas por meio da instalação de 8 coletores de $1 \mathrm{~m}^{2}$, os quais foram monitorados mensalmente durante um ano (maio 2009 a abril de 2010). As amostras coletadas foram secadas e separadas em categorias (frações) de folhas, galhos e miscelâneas (flores, frutos, sementes, pequenos pedaços de casca de árvores e insetos mortos). Destaca-se, que o sistema de Faxinal é um sistema silvopastoril característico da Região Centro-Sul do Estado do Paraná, onde há consórcio entre criação extensiva de animais, em áreas comunitárias e extração florestal dentro do criadouro comum. Há um fluxo contínuo de animais neste sistema, onde são criados soltos (sem restrições de propriedades). Conclui-se que, alguns meses foram identificados sendo os maiores produtores de serrapilheira, como é o caso do mês de outubro. A produção média de serrapilheira foi 6,097 t/ha. Os animais influenciam de forma efetiva na exposição do solo em áreas de faxinal.

Palavras-chave: Floresta Ombrófila Mista; Faxinal; Serrapilheira; Exposição do solo; Avaliação Sazonal.

ABSTRACT: This study aimed to estimate the production of litter in a fragment of the Florets Ombrofila Mista in the area of System Faxinal in municipality of the Prudentopolis- PR and the influence of soil animals on display. The collections were made through the installation of 8 collectors $1 \mathrm{~m}^{2}$, which were monitored monthly for one year. The samples were dried and separated into categories (fractions) of leaves, branches and miscellaneous (flowers, fruits, seeds and small pieces of bark the tree and dead insect). The system Faxinal is a system silvopastoril characteristic of Centro-Sul of the State of Parana, where there is a association of extensive breeding of animals in communal areas, forest extraction in the polyculture breeding common and subsistence food. There is a continuous flow of animals in this system, which is created loose (without property restrictions). During the sampling campaigns, some months were identified as major producers of litter such as the month of october. The average litter production was 6.097 t/ha. The animals effectively influence the exposure of the soil in areas of Faxinal.

Keywords: Ombrofila mix forest; Faxinal; Litter; Soil exposure; Seasonal Assessment. 


\section{INTRODUÇÃO}

Estudos sobre a produção de serrapilheira têm sido desenvolvidos por diversos autores, em diferentes localidades geográficas, porém têm-se deparado com um importante obstáculo, que é a comparabilidade de dados (Dias e Oliveira Filho, 1997), por causa das diferentes metodologias aplicadas e dos distintos comportamentos dos ecossistemas. Estudos que busquem compreender a produção de serrapilheira em diferentes biomas regidos pelo mesmo comportamento climático, se tornam de grande importância para a compreensão e determinação de modelos regionais.

O sistema Faxinal, é uma forma de organização camponesa silvopastoril, com criação extensiva de animais em áreas comuns; extração de erva-mate e secundariamente de madeira nas áreas de criadouro comum e policultura alimentar de subsistência. Destaca-se que, a agricultura de subsistência é realizada fora dos domínios do Faxinal, denominado terras de plantar (CHANG, 1986).

A organização deste sistema se dá através do cercamento de toda a área do Faxinal, dentro do qual, funciona o criadouro comum, onde todos os proprietários têm o direito de criar seus animais (bovino, suíno, equino, etc.) á solta, não havendo cercas ou barreiras entre as propriedades. A vegetação pode variar em sua tipificação, tudo dependendo da intensidade de pastoreio e do grau de alteração causado pelas atividades extrativas vegetais.

Outro ponto a ser ressaltado, é a ação dos animais, que acabam se alimentando de algumas plantas e sementes encontradas pelo chão, impossibilitando a regeneração da flora. Portanto, a vegetação no Sistema de Faxinal se caracteriza apenas com o dossel, onde praticamente não existem sub-bosque e vegetação herbácea. A quase inexistência do sub-bosque e da vegetação herbácea acaba por promover uma variância nas condições hidrológicas na vegetação, que constitui o Sistema de Faxinal.

Destaca-se que, a perturbação nos ambientes florestais influencia nas características do solo, por haver uma alteração na deposição de serrapilheira, e, por conseguinte, uma redução da matéria orgânica, a qual implica na variação da estabilidade dos agregados, infiltração, perda de água e solo. Resultados de pesquisas destacam menor estabilidade dos agregados, quando há decréscimo de matéria orgânica (BAVER, 1968; GUERRA, 1998).

Inúmeras pesquisas vêm sendo realizadas, na tentativa de avaliar a deposição de serrapilheira em fragmentos de Floresta Ombrófila Mista, dentre as quais se destaca: Andrade e Krapfenbauer (1983), Britez et al.(1992); Fernandes e Backes (1998); Schumacher et.al (2004); Figueiredo Filho et. al. (2005).

Em ecossistemas florestais tropicais e subtropicais conservados ocorre uma produção contínua de serrapilheira no decorrer do ano (Werneck et al., 2001), cuja quantidade total produzida nas diferentes épocas depende do tipo de vegetação (Leitão-Filho et al., 1993). A quantidade de serrapilheira depositada também pode variar dentro de um mesmo tipo de vegetação, dependendo do grau de perturbação das áreas. Desta forma, o aporte de serrapilheira em áreas submetidas a distúrbios pode ser empregado como indicador visando avaliar o processo de recuperação da vegetação (MARTINS ; RODRIGUES, 1999).

Diversos estudos vêm sendo desenvolvidos, no intuito de avaliar a importância da serrapilheira nos condicionantes hidrogeomorfológicos em áreas florestadas como: interceptação da água em serrapilheira (MITCHEL e TELL, 1997) retenção de água em serrapilheira (COELHO NETTO, 1995; THOMAZ, ANTONELI, 2012), ciclagem de nutrientes (BARNES et.al., 1997), lixiviação de nutrientes (DICKOW et.al 2009), capacidade de armazenamento de umidade (VOIGHT e WALSH, 1976; BURGHOUTS et.al., 1994), infiltração e condicionamento de fluxos superficiais (RODRIGUES, 2005), perda de água e solo (WILDNER, 1985; ANTONELI, 2011), estabilidade de agregados (HARRIS, et.al 1966; BAVER 1968; GUERRA 1998).

Em fragmentos de Floresta Ombrófila Mista, nota-se que há uma gama de pesquisas acerca de diversas variáveis hidrológicas e geomorfológicas, como: produção de serrapilheira (WISNIEWSKI, et.al 1997; SCHUMACHER et.al. 2004; FIGUEIREDO FILHO et.al. 2005), micronutrientes (BRITEZ et.al.1992); composição e estrutura floresta (JARENKOW e BAPTISTA (1978), microclima do interior da Floresta (CESTARO 1988), produção de $\mathrm{CO}_{2}$ pela decomposição de matéria orgânica pela atividade biológica 
do solo (FERNANDES e BACKES 1998), estrutura fitossociológica e a regeneração (MAUHS e BACKES 2002), interceptação (SWANK, et al. 1972); perda de solo (ANTONELI 2011). No entanto são poucas as pesquisas desenvolvidas em Fragmentos de Floresta Ombrófila Mista com Sistema de Faxinal, por este ser uma forma de uso e ocupação característica da Região Centro-Sul do Estado Paraná.

O constante pisoteio, tanto nas áreas de pastagens, quanto nas áreas florestadas; acaba por promover uma alteração na compactação do solo (GREACEN e SANDS 1980) e na exposição do mesmo, principalmente nas áreas florestais, pois os animais acabam revolvendo a serrapilheira e se alimentando de algumas espécies de folhas e frutos (ANTONELI, 2011).

Cabe considerar, que o trânsito constante dos animais implica em uma dificuldade maior de regeneração, tanto das espécies arbóreas, quanto das gramíneas. Essa questão pode provocar o raleamento ou perda total da cobertura vegetal do solo. Essas áreas seriam mais suscetíveis à compactação e à erosão, decorrentes do pisoteio dos animais e da exposição do solo. De fato, a compactação do solo e a consequente erosão e perda de nutrientes têm sido apontados como um dos principais problemas relacionados ao Sistema Silvopastoril (BAGGIO, 1983).

Dentre os animais que são criados soltos no sistema de Faxinal, os Suínos são os que acabam promovendo maior exposição do solo, devido a remobilização do horizonte $\mathrm{O}_{2}$, (serrapilheira em decomposição). Essa exposição implica nos processos erosivos, como não há sub-bosque e vegetação herbácea, este solo exposto, sofre o impacto direto das gotas da água da chuva (efeito splash), o que contribui para a desagregação dos grumos do solo e reduz a infiltração, promovendo um aumento nas perdas de água e solo (ANTONELI 2011).

Por fim, segundo Thomaz (2007); Thomaz e Dias, (2009), nas condições atuais das florestas, que estão sob o domínio de Faxinal, na Região Centro-Sul do Estado do Paraná, são formas de sistema "silvopastoril" de nível tecnológico baixo a nulo. Muitas alterações são observadas neste sistema como: raleamento interno da floresta (estratos inferiores); redução do adicionamento de serrapilheira ao solo; mudança na interceptação da chuva; compactação do solo pelo pisoteio do gado; indução à formação de ravinas no caminho dos animais; desbarrancamento de margens em riachos; e aumento da carga sedimentar nos riachos. Todas estas questões, refletem na diminuição da rentabilidade para os faxinalenses ao comercializar seus rebanhos. Neste contexto, é necessário aumentar seus rebanhos, o que implica em uma maior pressão sobre as áreas de Faxinal (ANTONELI 2011).

Neste contexto, o presente artigo tem por objetivo, avaliar a produção de serrapilheira em uma Floresta Ombrófila Mista com domínio do Sistema de Faxinal, sendo que esta não possui sub-bosque, devido a dificuldade de regeneração da vegetação causada pela circulação constante dos animais domésticos (equinos, suínos, bovinos, caprinos e aves). E, como não há restrições de áreas para o pastoreio dos animais (criadouro comum), avaliou-se também a influência destes, na exposição do solo no interior da floresta.

Partiu-se do pressuposto, de que a deposição de serrapilheira apesar de ser constante ao longo do ano, pode apresentar variações de intensidade, em determinados períodos. Outra questão investigada é em relação à exposição do solo no interior da floresta, pois o aumento na produção de serrapilheira, pode não representar menor exposição, por haver variação na intensificação do pastoreio no interior da floresta ao longo do ano.

\section{CARACTERIZAÇÃO DA ÁREA DE ESTUDOS}

O município de Prudentópolis (onde a área de estudos está inserida), localiza-se na região Centro-Sul do Paraná, próximo à borda da Escarpa da Serra Geral, pertencendo ao extremo Oeste do $2^{\circ}$ Planalto Paranaense. É o terceiro maior município em área territorial do Paraná, com uma superfície de $2.275 \mathrm{~km}^{2}$. Situa-se a uma latitude de $25^{\circ} 12^{\prime} 47^{\prime \prime} \mathrm{S}$ e longitude de $50^{\circ} 58^{\prime} 40^{\prime \prime} \mathrm{W}$ (sede municipal) (Figura 1). O município é considerado tipicamente agrícola, por apresentar maior população residente na área rural, o qual é justificado pelo grau elevado de mão-de-obra empregada na agricultura. Fatores como clima, solo, relevo contribui para um "atraso" agrícola, além de algumas formas peculiares de uso e ocupação do solo, onde se encontra o Sistema de Faxinal, que é uma forma de apropriação e utilização dos recursos naturais utilizados pelos agricultores, não só do Município, mas que pode ser encontrado em toda a Região Centro sul do Estado do Paraná. 
Figura 1- Localização da área de estudos.

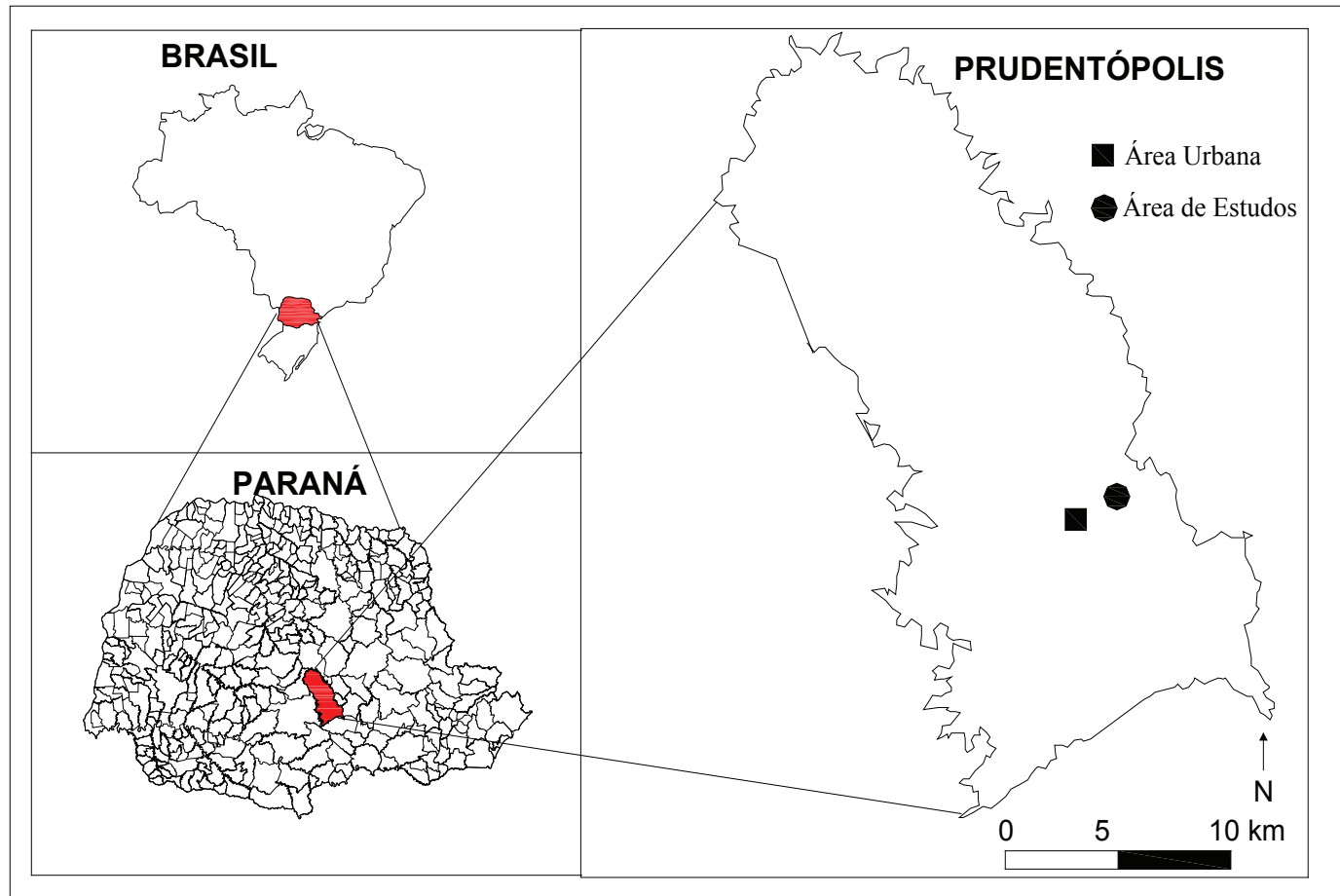

Org. dos autores.

O município é constituído por um percentual considerável de faxinais, por apresentar algumas peculiaridades importantes. Existem aqueles que atrelam estes percentuais, como uma forma de manter viva a concepção da realidade vivida pelos seus antepassados. Outros atribuem às características físicas como: clima ameno, relevo dissecado, além das dimensões das propriedades.

Segundo Souza (2007), em um relatório publicado após o $2^{\circ}$ Encontro dos Faxinalenses, em agosto de 2007, para identificar quantos são os faxinais, onde se localizam e como estão distribuídos geograficamente pelo Paraná. O total de faxinais em todo o Estado foi de 227, sendo divididos em diversas regiões do estado. Na micro-região de Prudentópolis a qual segundo o relatório estão inseridos os municípios de Prudentópolis, Imbituva, Teixeira Soares e Fernandes Pinheiro existem 28 faxinais, sendo que destes 14 (50\%) estão inseridos no município de Prudentópolis.

Este tipo de uso do solo indica uma vegetação esparsa, entremeadas por capões de mata (Floresta
Ombrófila Mista e áreas de pastagens. O Fragmento de Floresta Ombrófila Mista com domínio do Sistema de Faxinal onde a pesquisa foi realizada, se caracteriza por mata baixa, onde o pinheiro ocorre de modo esparso e apresenta menor porte. As espécies arbóreas e arbustivas mais comuns são: a congonha (Ilex theezans), carne-de-vaca (Cletra scabra), as capororocas (Rapanea spp), os guamirins (Gomidésia sellowiana e Myrceugenia euosma) e as caúnas (Ilex dumosa e Ilex microdonta). São entremeados de taquarais e carazais, bem como de vassouras, como o vassourão branco (Phitocarpha angustifolia), além das lauráceas, como as diversas espécies de canela. Vale ressaltar, que as Florestas Ombrófila Mista (Mata de Araucária), na área em estudo não apresenta formação homogênea e contínua, mas compõe-se de diversos tipos de sub-matas.

A floresta Ombrófila Mista em estudo, apresenta um dossel em torno de 18 metros de altura, e possui uma população em torno de 420 indivíduos por hectare com DAP $\geq 22 \mathrm{~cm}(\mathrm{n}=50)$ 
Os solos se caracterizam predominantemente em Cambissolos, Luvissolo, Neossolo e Espodossolo nas áreas de várzeas (EMBRAPA, 1999), sendo na maioria rasos e pouco desenvolvidos, influenciados pela estrutura geológica e pelo predomínio de um regime climático subtropical, fatores que propiciam um lento processo de intemperização e formação de solos. O clima, segundo classificação de Köppen é $\mathrm{Cfb}$ (Mesotérmico úmido com verão ameno). Chuvas uniformemente distribuídas, sem estação seca e a temperatura média do mês mais quente não chega a $22^{\circ} \mathrm{C}$. (Geadas severas e frequentes, num período médio de ocorrência de 10 a 25 dias anualmente). A pluviosidade histórica, gira em torno de $2057 \mathrm{~mm}$ anuais (Antoneli, 2011).

\section{MATERIAL E MÉTODO}

\section{Produção de serrapilheira}

Para avaliar a produção de serrapilheira na Floresta com domínio de Faxinal, aplicou-se a técnica de parcelas coletoras com área de $1 \mathrm{~m}^{2} \mathrm{O}$ coletor foi confeccionado com uma moldura de madeira, sendo fixada uma tela de "nylon" com malha de $2 \mathrm{~mm}$, formando um saco cônico de $0,5 \mathrm{~m}$ de profundidade. Sendo este preso em quatro pedestais fixados no chão, a uma altura de aproximadamente $1,5 \mathrm{~m}$ do solo. (Figura 2).

Figura 2. Coletor instalado no interior da floresta Ombrófila Mista

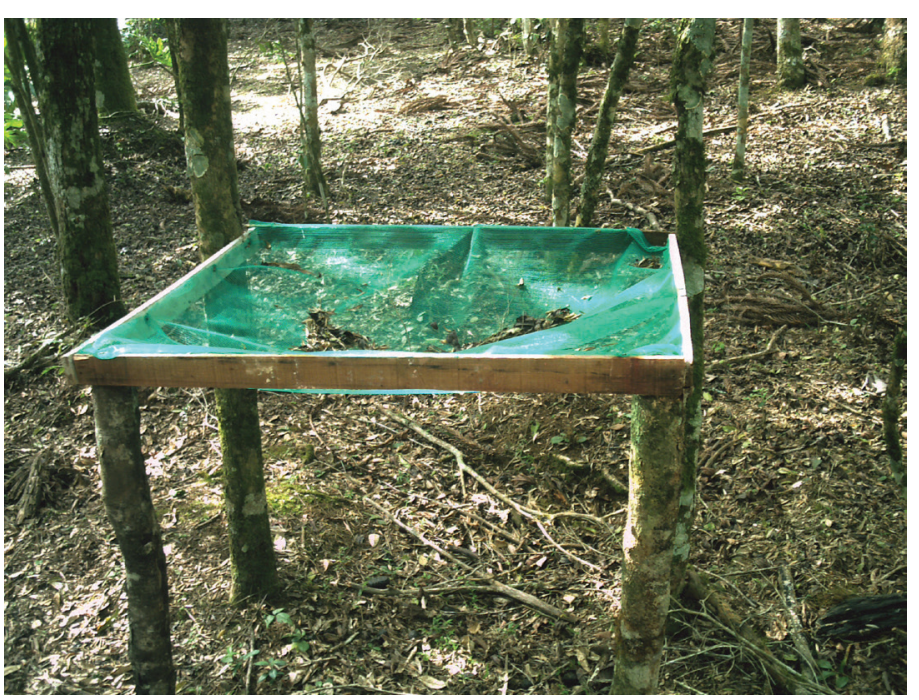

Fonte Antoneli. (2011).

As coletas foram efetuadas mensalmente e, após uma pré-secagem, o material de cada coletor foi separado em três frações: folhas, galhos, miscelânea (flores, frutos, sementes). Cada fração foi embalada em sacos de papel, levada à estufa a uma temperatura de $65^{\circ} \mathrm{C}$, para eliminação da umidade. Foram distribuídos aleatoriamente 8 coletores em uma parcela de 0,5 hectare. O monitoramento foi realizado de maio de 2009 a abril de 2010 .

Devido ao pisoteio e ao revolvimento da serrapilheira ao longo do ano promovido pelos animais; verificou-se que nas áreas florestais, com domínio do Sistema de Faxinal, apresentavam uma exposição maior do solo em relação às áreas florestais sem criação de animais de forma extensiva (ANTONELI 2011).

\section{Avaliação da exposição do solo}

Para avaliar o percentual de exposição do solo, adaptou-se (construiu-se) um quadro de madeira (1x1m), (Figura 3). Neste quadro foram feitas subdivisões a cada $10 \mathrm{~cm}$, formando uma malha de 100 quadros menores de $100 \mathrm{~cm}^{2}$ cada. A partir dessa malha, foi realizada a avaliação da exposição do solo em $1 \mathrm{~m}^{2}$. 
Figura 3- Amostrador de exposição do solo sendo utilizado em área de fumicultura.

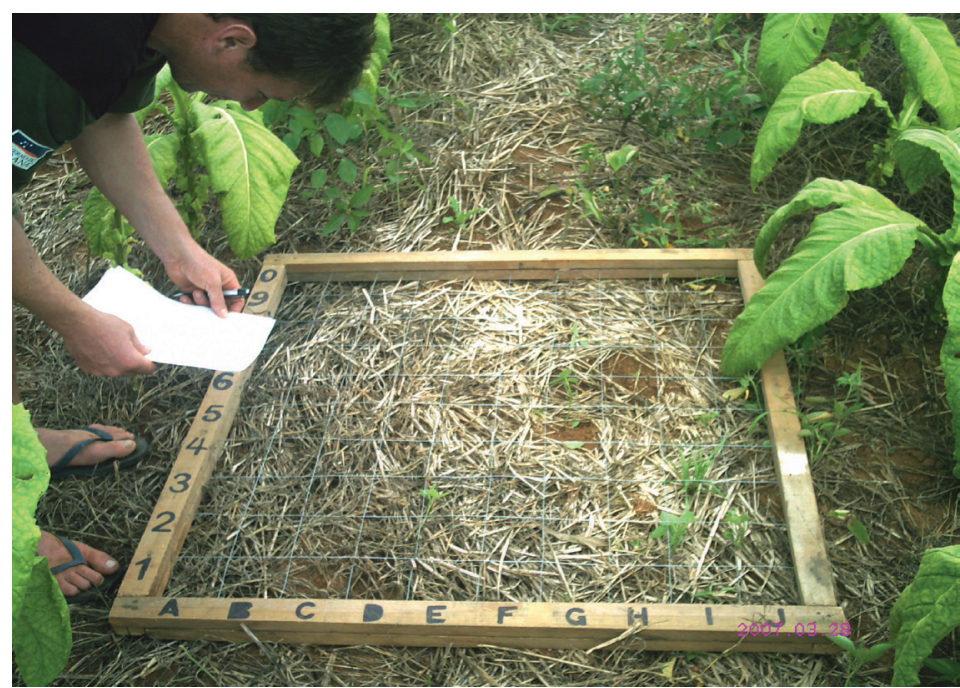

Fonte Antoneli. (2011).

Os dados foram representados em um croqui, sendo anotado o percentual de exposição de cada quadro menor $\left(100 \mathrm{~cm}^{2}\right)$. Para estipular o percentual de exposição dentro desses quadros menores, foi realizada uma avaliação visual, indicando um valor aproximado do percentual de exposição. Ao término da avaliação dos 100 (cem) quadros menores, somou-se todos os valores estimados e dividiu-se pelo número total de quadros. O resultado do percentual de exposição do referido ponto $\left(1 \mathrm{~m}^{2}\right)$ foi estimado pela equação 1 .

$$
\begin{aligned}
& \qquad P \exp =\frac{\sum^{n-1} q m}{N q} q \text { equação } 5 \\
& \text { Onde: } \\
& \text { Pexp }=\text { Porcentagem de exposição do solo em } 1 \mathrm{~m}^{2} \\
& \sum^{n-1} q m=\text { Somatório da exposição dos quadros menores }\left(100 \mathrm{~cm}^{2}\right) \\
& N q=\text { Número total de quadros menores do equipamento }(100)
\end{aligned}
$$

As coletas foram realizadas mensalmente de forma aleatória na área de Faxinal, sendo avaliado cerca de 10 pontos a cada coleta. Este procedimento serviu para identificar as variações na exposição do solo.

\section{RESULTADOS E DISCUSSÕES}

\section{Produção de serrapilheira}

Após o monitoramento mensal da produção de serrapilheira na floresta de Faxinal, verifica-se que os valores encontrados condizem com aqueles registrados na literatura, o que diferencia são as características da vegetação e a forma de uso e ocupação da mesma. (Tabela 1).

A produção total de serrapilheira, monitorada na Floresta Ombrófila Mista no Sistema de Faxinal, foi de 6,096 t/ha/ano, sendo que a produção de serrapilheira, foi constante o ano todo, com variações mensais de deposição. Alguns meses apresentaram maior deposição, como é o caso dos meses de agosto, outubro e dezembro $(17,3 \%, 15,2 \%$ e $13,2 \%)$ respectivamente. Já os meses de fevereiro e abril, indicaram menores percentuais de deposição 4,0\% e 4,1\% respectivamente.

A produção total de folhas foi de 3,698 (t/ ha), um percentual de $60,6 \%$, sendo que os meses de setembro, outubro e novembro, indicaram os maiores percentuais $(11,2 \%, 19,9,12,0 \%$ respectivamente). $\mathrm{O}$ restante dos meses houve uma variação pequena entre os valores de deposição. A produção total de galhos, foi de $1,464 \mathrm{t} / \mathrm{ha}$, cerca de $24,0 \%$, indicando os meses de agosto e dezembro como os de maior produção (25,2\%, 29,9\% respectivamente). Já alguns meses, apresentaram valores muito baixos, como é o caso dos meses de junho, julho e fevereiro com deposição de $2,1 \% 2,2 \%$ e $1,7 \%$ respectivamente. A deposição de miscelânea indicou um percentual em torno $15,3 \%$. Destaca-se que deste percentual, 47,5 foi produzido pelo mês de agosto, já alguns meses indicaram percentuais muito baixos de produção, como é o caso dos meses de maio, junho e julho com $0,7 \%, 1,1 \%$ e $0,8 \%$ respectivamente. 
Tabela 1 - produção de serrapilheira mensal total dividida em sub-classes.

Tabela 1- produção de serrapilheira mensal total dividida em sub-classes.

\begin{tabular}{|c|c|c|c|c|c|}
\hline mês & $\begin{array}{l}\text { Folhas } \\
\left(\mathrm{g} / \mathrm{m}^{2}\right)\end{array}$ & $\begin{array}{c}\text { Galhos } \\
\left(\mathrm{g} / \mathrm{m}^{2}\right)\end{array}$ & $\begin{array}{l}\text { Miscelânea } \\
\left(\mathrm{g} / \mathrm{m}^{2}\right)\end{array}$ & $\begin{array}{l}\text { Total } \\
\left(\mathrm{g} / \mathrm{m}^{2}\right)\end{array}$ & $\begin{array}{l}\text { Chuva } \\
\text { (mm) }\end{array}$ \\
\hline Mai/09 & $22,7 \pm 15,1$ & $8,8 \pm 3,8$ & $0,6 \pm 0,1$ & $32,3 \pm 5,5$ & 120,0 \\
\hline Jun/09 & $34,1 \pm 13,7$ & $3,1 \pm 2,7$ & $1,0 \pm 0,2$ & $38,3 \pm 4,7$ & 125,5 \\
\hline $\mathrm{Jul} / 09$ & $22,2 \pm 6,4$ & $3,2 \pm 3,1$ & $0,8 \pm 1,0$ & $26,3 \pm 4,2$ & 345,0 \\
\hline Ago/09 & $24,3 \pm 9,0$ & $36,8 \pm 16,5$ & $44,4 \pm 4,9$ & $105,6 \pm 19,1$ & 105,0 \\
\hline Set/09 & $41,2 \pm 21,1$ & $3,7 \pm 2,1$ & $1,9 \pm 2,1$ & $46,9 \pm 8,1$ & 360,6 \\
\hline Out/09 & $73,7 \pm 37,6$ & $7,5 \pm 3,5$ & $11,3 \pm 2,7$ & $92,5 \pm 7,1$ & 230,1 \\
\hline Nov/09 & $44,3 \pm 20,0$ & $13,1 \pm 6,1$ & $4,4 \pm 1,4$ & $61,9 \pm 19,7$ & 142,0 \\
\hline Dez/09 & $27,5 \pm 8,7$ & $43,7 \pm 7,9$ & $9,4 \pm 2,6$ & $80,6 \pm 21,4$ & 155,0 \\
\hline $\mathrm{Jan} / 10$ & $21,2 \pm 11,2$ & $6,2 \pm 2,8$ & $12,5 \pm 2,9$ & $40,0 \pm 7,5$ & 165,0 \\
\hline Fev/10 & $19,3 \pm 4,7$ & $2,5 \pm 2,1$ & $2,5 \pm 1,5$ & $24,4 \pm 3,4$ & 125,5 \\
\hline Mar/10 & $20,0 \pm 9,4$ & $13,7 \pm 1,1$ & $2,5 \pm 2,0$ & $36,3 \pm 3,7$ & 240,4 \\
\hline Abr $/ 10$ & $18,7 \pm 13,4$ & $3,7 \pm 3,1$ & $2,3 \pm 1,8$ & $24,8 \pm 2,1$ & 300,1 \\
\hline Total $\left(\mathrm{g} / \mathrm{m}^{2}\right)$ & $369,8 \pm 25,1$ & $146,4 \pm 17,2$ & $93,5 \pm 2,1$ & $609,7 \pm 43,9$ & 2414,2 \\
\hline Total (t/ha) & 3,698 & 1,464 & 0,093 & 6,097 & - \\
\hline
\end{tabular}

Nota: média seguida de desvio padrão; Número de amostras 8 .

Nota: $\mathrm{N}=8$

O total de produção de serrapilheira e o percentual de deposição de folha encontrada por esta pesquisa, foram confrontados com algumas pesquisas já realizadas (Tabela 2).

Tabela 2- Contribuição da deposição total de folhas em ecossistemas florestais.

\begin{tabular}{|c|c|c|c|}
\hline Fonte & $\begin{array}{c}\text { Produção de } \\
\text { Serrapilheira } \\
\text { (t/ha) }\end{array}$ & $\begin{array}{c}\text { Fração } \\
\text { de folhas } \\
\text { em (\%) }\end{array}$ & Floresta/localização \\
\hline $\begin{array}{l}\text { Martins e Rodrigues } \\
\text { (1999) }\end{array}$ & 5,968 & 64,9 & Floresta Est. Semidecidual- SP \\
\hline Pagano (1989) & 8,347 & 62,0 & $\begin{array}{l}\text { Floresta Mesófila Semidecidual } \\
\text { (SP) }\end{array}$ \\
\hline $\begin{array}{l}\text { Mazurec } \\
(1998)\end{array}$ & 9,460 & 67,7 & $\begin{array}{l}\text { Flor Est semidecidual de } \\
\text { encostas (RJ) }\end{array}$ \\
\hline $\begin{array}{l}\text { Wisniewski et. al. } \\
\text { (1997) }\end{array}$ & 7,240 & 57,0 & Floresta Ombrófila Mista (PR) \\
\hline Cunha et.al (1993) & 7,760 & 66,0 & $\begin{array}{l}\text { Floresta Estacional Decidual } \\
\text { (RS) }\end{array}$ \\
\hline $\begin{array}{l}\text { Fernandes e Backes } \\
\text { (1998) }\end{array}$ & 5,900 & 54,7 & Floresta Ombrófila Mista (RS) \\
\hline $\begin{array}{l}\text { Figueiredo Filho et.al } \\
(2005)\end{array}$ & 6,331 & 57,0 & Floresta Ombrófila Mista (PR) \\
\hline $\begin{array}{l}\text { Pezzatto e Wisniewski } \\
(2006)\end{array}$ & 11,700 & & $\begin{array}{l}\text { FlorestaEstacional } \\
\text { Semidecidual-Oeste do Paraná }\end{array}$ \\
\hline Portes et al. (1998) & 4,500 & 63,0 & $\begin{array}{l}\text { Mata Atlântica Altomontana } \\
\text { (PR) }\end{array}$ \\
\hline Este Estudo & 6,099 & 60,6 & $\begin{array}{l}\text { Floresta Ombrófila Mista com } \\
\text { domínio de Faxinal (PR) }\end{array}$ \\
\hline
\end{tabular}

Org. dos autores. 
Os valores encontrados por esta pesquisa foram confrontados com outras pesquisas realizadas em florestas, que apresentam características semelhantes à Floresta Ombrófila Mista, não sendo confrontados com produção de serrapilheira de Florestas em áreas de baixa latitude. Nota-se, que os valores encontrados por este estudo condizem com aqueles apresentados pelos autores citados.

Os dados de deposição de serrapilheira foram agrupados sazonalmente, a fim de identificar a possível influência da precipitação nas deposições sazonais. (Tabela 3).

Tabela 3- deposição sazonal de serrapilheira.

\begin{tabular}{|c|c|c|c|c|c|c|c|c|c|}
\hline Estação & $\begin{array}{c}\text { Folhas } \\
\left(\mathrm{g} / \mathbf{m}^{2}\right)\end{array}$ & $\%$ & $\begin{array}{c}\text { Galhos } \\
\left(\mathrm{g} / \mathbf{m}^{2}\right)\end{array}$ & $\%$ & $\begin{array}{c}\text { Miscelânea } \\
\left(\mathrm{g} / \mathbf{m}^{2}\right)\end{array}$ & $\%$ & $\begin{array}{r}\text { Total } \\
\left(\mathrm{g} / \mathrm{m}^{2}\right)\end{array}$ & $\%$ & $\begin{array}{c}\text { Chuva } \\
\text { (mm) }\end{array}$ \\
\hline Out & 61,5 & 16,6 & 26,4 & 18,0 & 5,4 & 5,8 & 93,3 & 15,3 & 660 \\
\hline Inverno & 80,8 & 21,8 & 43,2 & 29,5 & 46,2 & 49,4 & 170,1 & 27,9 & 575 \\
\hline Primava & 159,3 & 43,1 & 24,4 & 16,6 & 17,5 & 18,7 & 201,3 & 33,0 & 732 \\
\hline Verão & 68,1 & 18,4 & 52,5 & 35,9 & 24,4 & 26,1 & 145,0 & 23,8 & 445 \\
\hline Total & 369,8 & 100 & 146,5 & 100 & 93,5 & 100 & 609,7 & 100 & 2412 \\
\hline
\end{tabular}

Org. dos autores.

Por meio da tabela 2, nota-se que a produção total de serrapilheira indica maior produção na primavera com 201,3 g/m² (33,0\%), este maior índice, é atribuído à produção significativa de folhas que se extraído o percentual do período de primavera entre as três classes, é responsável por 79,1\% do total, enquanto que a produção de galhos foi responsável por $12,1 \%$ e a miscelâneas com apenas $8,7 \%$.

A produção de galhos na primavera foi representada por $16,4 \%$ (menor valor) e a produção de miscelânea neste período foi a segunda menor produção desta classe entre as estações com 17,5\%, sendo superior apenas ao outono que indicou porcentagem de 5,8\%. Já o outono, apresentou menor deposição total $(15,3 \%)$, sendo que neste período, as folhas indicaram um percentual em torno de 16,6 (menor valor). O mesmo caso ocorreu na classe de miscelânea, que teve menor valor também $(5,8 \%)$.

O maior percentual de deposição de serrapilheira na primavera, já havia sido justificado por BRUN et al. (2001), que ao relacionarem fatores climáticos à deposição de serrapilheira em diferentes estágios sucessionais de uma área de Floresta Estacional Decidual no Rio Grande do Sul, onde concluíram que, o principal mecanismo que desencadeia o processo de deposição de maior quantidade de serrapilheira na primavera é a detenção do crescimento provocada pelo inverno, além de outros fatores climáticos.
A produção de folhas da primavera foi $49,4 \%$ superior ao inverno (segunda maior deposição), este aumento pode ser atribuído à característica das espécies (caducifólias) que acabam por perder boa parte de suas folhas nos meses mais frios. Já a produção de galhos, indicou o verão como o período de maior deposição, este valor pode ser atribuído à intensidade das chuvas que apesar de não ser monitorada se caracterizam como chuvas convectivas nesta época do ano, as quais apresentam maiores intensidades e geralmente estão associadas a rajadas de ventos mais fortes (ANTONELI, 2011). Já a miscelânea, indicou maior produção no inverno (49,4\%), atribui-se este maior valor porque o inverno é uma estação de transição entre o período de produção de frutos (início do inverno) e de florada (final do inverno).

A produção sazonal se portou de forma parecida em relação aos dados apresentados por Figueiredo Filho et. al. (2005), no qual os autores encontraram uma sequência de maior para menor índice, a qual apresenta primavera, inverno, verão e outono. Britez et al. (1992) em suas pesquisas vem contribuir para esta questão, onde os pesquisadores, ao correlacionarem a maior queda durante a primavera, com o aumento da pluviosidade e da temperatura, à presença de espécies decíduas e a formação de geadas. A sazonalidade na produção de serrapilheira tem sido relacionada às características climáticas do ambiente estudado (SPAIN, 
1984), assim com a baixa disponibilidade de nutrientes, deciduidade das espécies e estágio sucessional (VOGT et., al 1996).

Ao correlacionar o índice de pluviosidade com os percentuais de produção de serrapilheira, nota-se que há uma baixa correlação entre ambos $(r=0,226)$. Quando correlacionados os valores de cada classe de serrapilheira com a precipitação tem-se: $r=0,101$ entre precipitação e folhas; $r=0,207$ entre galhos e precipitação e $r=0,376$ entre a precipitação e a miscelânea. Através desta baixa correlação conclui-se que a chuva não atua de maneira significativa na produção de serrapilheira.

A produção de serrapilheira segue um padrão climatobotânico, ou seja, as espécies existentes na floresta Ombrófila Mista são adaptadas ao clima ameno. Nos meses de inverno, onde a produção de serrapilheira é maior, porque grande parte das espécies perdem suas folhas neste período (árvores caducifólias).

Andrade et.al.(2000), vem contribuir com esta questão ao estimarem a produção de serrapilheira da Mimosa caesalpiniifolia. Os autores encontraram correlação maior nos meses mais frios com menor precipitação, os quais podem ter estimulados as plantas à queda do material senescente. Chabot e Hicks (1982) citaram que folhas individuais sofrem abscisão, por razões que incluem além de danos físicos, estresses causados por baixas temperaturas e/ou déficit hídrico, que promovem desordem na atividade celular, induzindo a senescência. Portanto, o comportamento estacional da produção de serrapilheira, decorre principalmente, do comportamento da fração foliar, visto que esta é a constituinte mais importante da serrapilheira e que apresenta resposta mais definida às condições climáticas (CIANCIARUSO et.al., 2005).

No entanto, a precipitação na área de estudo não apresenta déficit hídrico, o que influencia na baixa correlação da produção de serrapilheira com a precipitação. Esta baixa correlação tem sido discutida por diversos autores tais como: PAGANO (1989); TREVISAN (1998).

Outra questão que deve ser levada em consideração é a idade da floresta. Devido a dificuldade de regeneração das espécies ocasionadas pelo constante pastoreio, nota-se que há um envelhecimento dos indivíduos, o que pode promover uma variação de produção de serrapilheira. CARPANEZZI (1997), conclui que, existe um padrão de produção de serrapilheira relacionado com a idade dos indivíduos, onde a taxa de deposição e o valor máximo de deposição são próprios para cada caso e, posteriormente, o valor da deposição de folhas estabiliza-se ou diminui lentamente nas espécies mais avançadas da sucessão (mais velhas).

\section{Exposição do solo}

Por se tratar de uma área de florestas com domínio do sistema de Faxinal, há um pastoreio constante ao longo do ano (sem rodízio de terras e restrições de animais), implicando em alternância na exposição do solo no interior da floresta (Tabela 4). Cabe considerar que os animais permanecem boa parte do tempo nas áreas de florestas, pois estas podem fornecer sombra em períodos quentes e proteção contra o frio, no período de inverno. Essa questão foi evidenciada por WIDOWSKI (2001), quando analisou os hábitos de pastejo de pares de vacas e bezerros de corte durante 24 dias, em pastagens com e sem acesso à sombra, em clima temperado. Os resultados mostraram que o tempo gasto à sombra, foi proporcional à temperatura do ar. 
Tabela 4- Exposição do solo no interior da floresta.

\begin{tabular}{|c|c|c|c|c|c|c|c|c|c|}
\hline mês & $\begin{array}{l}\text { Exp. } \\
\text { P1 } \\
(\%)\end{array}$ & $\begin{array}{l}\text { Exp. } \\
\text { P2 } \\
(\%)\end{array}$ & $\begin{array}{l}\text { Exp. } \\
\text { P3 } \\
(\%)\end{array}$ & $\begin{array}{l}\text { Exp. } \\
\text { P4 } \\
(\%)\end{array}$ & $\begin{array}{l}\text { Exp. } \\
\text { P5 } \\
(\%)\end{array}$ & $\begin{array}{l}\text { Exp. } \\
\text { P5 } \\
(\%)\end{array}$ & $\begin{array}{l}\text { Exp. } \\
\text { P7 } \\
(\%)\end{array}$ & $\begin{array}{l}\text { Exp. } \\
\text { P8 } \\
(\%)\end{array}$ & $\begin{array}{l}\text { Média } \\
\text { de Exposição } \\
(\%)\end{array}$ \\
\hline mai/09 & 30 & 26,1 & 32 & 27,1 & 25 & 25,4 & 30,1 & 35,1 & $28,9 \pm 3,3$ \\
\hline jun/09 & 32,6 & 29,1 & 37,1 & 30,1 & 25,1 & 26,4 & 32,1 & 38,7 & $31,4 \pm 4,5$ \\
\hline jul/09 & 34,5 & 32,2 & 40,1 & 35,4 & 29,1 & 28,1 & 34,6 & 38,5 & $34,1 \pm 3,9$ \\
\hline ago/09 & 38,1 & 32,5 & 38,1 & 36,7 & 30,1 & 29,4 & 29,8 & 39,8 & $34,3 \pm 4,0$ \\
\hline set/09 & 35,1 & 34,5 & 38,7 & 40,5 & 32,5 & 30,8 & 31,1 & 40,9 & $35,5 \pm 3,8$ \\
\hline out/09 & 30,1 & 35,1 & 39,8 & 39,4 & 31,9 & 29,1 & 33,5 & 42,1 & $35,1 \pm 4,5$ \\
\hline nov/09 & 31,5 & 32,1 & 35,1 & 36,9 & 29,4 & 28,3 & 31,0 & 39,5 & $33,0 \pm 3,6$ \\
\hline dez/09 & 27,5 & 30,8 & 32,1 & 35,2 & 26,1 & 27,6 & 28,2 & 35,4 & $30,4 \pm 3,4$ \\
\hline jan/10 & 25,4 & 29,1 & 32,6 & 34,6 & 24,8 & 25,0 & 26,0 & 34,1 & $29,0 \pm 4,0$ \\
\hline fev/10 & 24,9 & 28,7 & 30,1 & 33,0 & 24,0 & 24,7 & 26,0 & 33,0 & $28,1 \pm 3,5$ \\
\hline $\operatorname{mar} / 10$ & 24,1 & 27,2 & 29,8 & 33,1 & 24,2 & 23,9 & 25,4 & 32,4 & $27,5 \pm 3,5$ \\
\hline abr/10 & 24 & 27,1 & 29,4 & 33,0 & 21,1 & 24,0 & 25,3 & 32,1 & $27,0 \pm 3,9$ \\
\hline Média & 30,9 & 31,0 & 35,5 & 34,9 & 26,9 & 27,4 & 30,2 & 37,7 & $31,9 \pm 3,5$ \\
\hline
\end{tabular}

Org. dos autores.

Por meio da tabela 4, nota-se que a variação da exposição do solo ao longo do ano nas áreas de floresta sob influência do pastoreio, foi relativamente baixa, sendo que a menor exposição do solo foi encontrada no mês de abril $(27,0 \%)$ e a maior, no mês de setembro com (35,5\%), uma variação de $8 \%$. Observou-se em caminhamentos pela área de estudo que algumas espécies de árvores como a guabirobeira (Campomanesia xantocarpa), figueira, (Ficus guaranitica) jabuticabeira (Plinia trunciflora), araucária (Araucaria angustifolia) dentre outras espécies frutíferas, servem como complemento alimentar para os animais, o que contribui para uma movimentação maior destes animais no interior da floresta, em busca dessa fonte de alimento. Este pisoteio, acaba fracionando a serrapilheira depositada na superfície do solo, promovendo algumas "manchas" de exposição do solo.

Outro fator observado, que pode ter potencializado a exposição do solo no interior da floresta, é, em relação às condições climáticas da região, pois durante o inverno, é comum a ocorrência de geadas, que acabam prejudicando as gramíneas nos locais de clareiras (pastagem natural sem estrato arbóreo). Isso implica, em uma maior mobilização dos animais no interior da floresta em busca de alimento, potencializando a exposição do solo. LANZANOVA (2005) chama a atenção para o fato de o animal (gado), além do pisoteio, devido sua mobilização em busca de alimento, os animais acabem se deitando para ruminar o alimento, sendo feita geralmente em posição de repouso a sobra. Estas questões acabam implicando em uma maior exposição do solo, mesmo que, a deposição de serrapilheira seja maior em determinados períodos.

Para evidenciar esta questão, foram correlacionados os dados de exposição do solo com os dados de produção de serrapilheira (Figura 4). 
Figura 4- Correlação entre produção de serrapilheira e exposição do solo

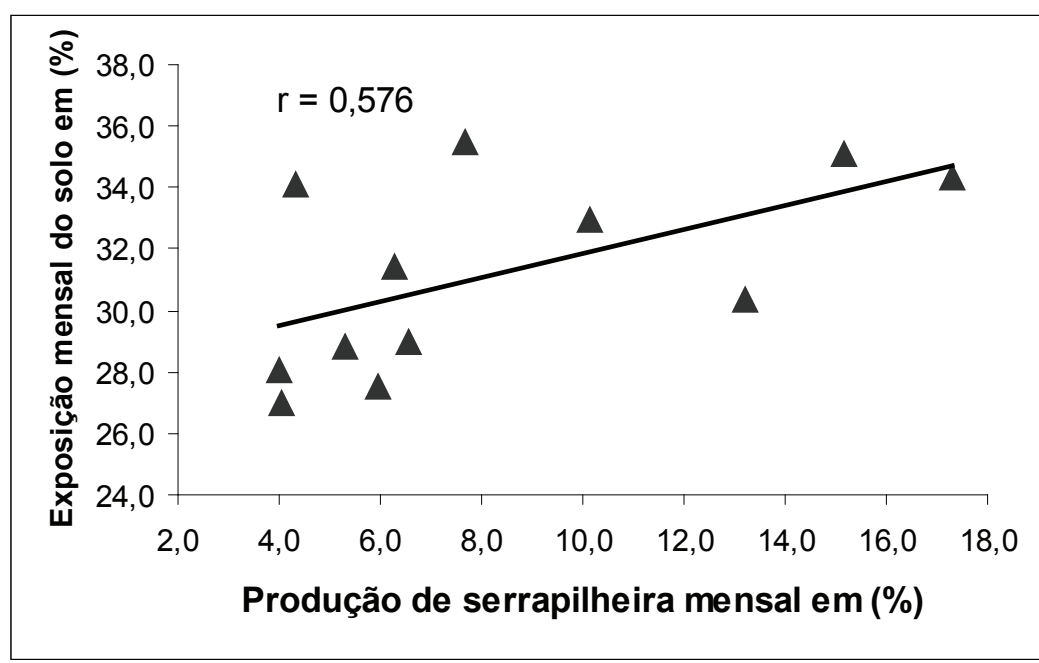

Org. dos autores.

Por meio da figura 4, verifica-se que há uma correlação média $(r=0,576)$, entre a deposição da serrapilheira e a exposição do solo. Nota-se, que o aumento na produção de serrapilheira, potencializa a exposição do solo, ou seja, em determinados períodos, onde há um aumento na produção de serrapilheira, há, por conseguinte, um aumento da exposição do solo.

Grosso modo, se há um aumento na produção de serrapilheira, deveria haver uma menor exposição do solo, mas em caminhamentos pela área de estudo, percebeu-se que os animais, utilizam a floresta com maior intensidade justamente nos períodos de maior produção de serrapilheira. Para evidenciar esta questão foram confrontadas as porcentagens sazonais de produção de serrapilheira com a porcentagem de exposição do solo. (Tabela 5).

Tabela 5-Exposição sazonais do solo e produção sazonal de serrapilheira.

\begin{tabular}{ccc}
\hline estações & $\begin{array}{c}\text { Exposição do solo } \\
(\%)\end{array}$ & Produção de serrapilheira (\%) \\
\hline Outono & 27,8 & 15,3 \\
Inverno & 33,3 & 27,9 \\
Primavera & 34,5 & 33,0 \\
Verão & 29,8 & 23,8 \\
\hline
\end{tabular}

Org. dos autores.

Evidencia-se na tabela 5, a ação dos animais na exposição do solo, pois os períodos de maior deposição de serrapilheira condizem com os períodos de maior exposição. Os períodos de inverno e primavera foram os que apresentaram maior exposição do solo no interior da floresta, no entanto foram os períodos de maior deposição. Em caminhamento pela área de estudos ao longo do monitoramento, observou-se que, nos períodos mais frios há uma mobilização maior dos animais nas áreas florestadas, em busca de abrigo para se protegerem do frio. Outra questão que pode influenciar na variação da exposição do solo, é a utilização dos animais (equinos) nas tarefas diárias da lavoura, isso promove uma menor pressão nas áreas tanto de pastagens quanto nas áreas de florestas com domínio de Faxinal.

A tração animal é utilizada em grande escala nas atividades agrícolas, onde predomina na região o 
cultivo do tabaco (Nicotina tabacun) e, esta atividade é sazonal, pois se desenvolve entre os meses de setembro a março. O restante dos meses é chamado pelos agricultores de "período de folga". Neste contexto, durante o inverno, os animais são poucos utilizados, permanecendo maior parte do tempo, nas áreas de Faxinal que são denominadas de "potreiros".

Antoneli (2011), ao monitorar a perda de água e solo em áreas de floresta com domínio de Faxinal, concluiu que há uma variação sazonal nas perdas, e dentre outras variáveis que atuam nesta sazonalidade está a influência dos animais nas perdas, pois em períodos de cultivo do tabaco, as perdas foram menores e durante o período de "folga" (abril a agosto), as perdas forma maiores.

\section{CONCLUSÃO}

A produção de serrapilheira encontrada na Floresta Ombrófila Mista com sistema de Faxinal, foi de 6,096 t/ha/ano, condizendo com os valores apresentados na literatura, apesar de esta forma de vegetação indicar algumas especificidades. Ou seja, mesmo sendo Faxinal não ocorre diminuição do adicionamento de serrapilheira pela ausência do sub-bosque.

As folhas foram responsáveis pela maior parte da serrapilheira produzida pela floresta, seguindo-se os galhos e miscelânea, $(61 \%, 24 \%$ e $15 \%$ respectivamente). Na avaliação da deposição estacional, seguiu a ordem decrescente primavera $>$ verão $>$ inverno $>$ outono.

Com relação aos percentuais de exposição do solo, conclui-se que o constante trânsito dos animais devido ao acesso livre s áreas florestais, promove uma exposição maior do solo, mesmo nos períodos em que há um aumento na deposição de serrapilheira.

A exposição de 25 a $35 \%$ (menor e maior exposição), é considerada alta em área de floresta, no entanto são escassas as pesquisas que avaliam a exposição do solo nesse ambiente. Portanto os valores de exposição encontrados acabam sem parâmetros de comparação.

\section{REFERÊNCIAS}

ANDRADE, A.G; COSTA,,G.S; FARIA, S.M. Deposição e decomposição de serrapilheira em povoamento de Mimosa caesalpiniifolia, Acácia mangium e Acácia holosericea em quatro anos de idade em planossolo. Revista Brasileira de ciência do solo. v.2 n4 p777785, 2000.

ANDRADE, F.H.; KRAPFENBAUER, A. Inventário de um reflorestamento de araucária de 17 anos em Passo Fundo-RS. Parte II: Inventário de nutrientes. Pesquisas Austríacobrasileiras. Ed. Única. Áustria, 1983. p.30-35.

ANTONELI, V. Dinâmica do uso da terra e a produção de sedimentos em diferentes áreas fontes na bacia hidrográfica do Arroio Boa Vista- Guamiranga-PR. Tese Doutorado Universidade Federal do Paraná UFPR. Curitiba 2011. 354 p

BAGGIO, A. J. Sinopse de algumas vantagens e desvantagens dos sistemas silvipastoris com Pinus spp. Curitiba: EMBRAPA-URPFCS,1993, 10 p. (EMBRAPA-URPFCS. Circular Técnica, 7).

BARNES, B. V.; ZAK, D. R.; DENTON, S.R.; SPURR, S. H. Forest Ecology. Oxford. John Wiley e Sons. 1997.

BAVER. L.D. The effect of organic matter on soil structure: In. Progressos em Biodinâmicas e Produtividade dos solos, I. Santa Maria RS. Anais..., Santa Maria 1968, p 191- 206.

BRITEZ, R. M.; REISSMANN, C.B.; SILVA, S. M.; SANTOS FILHO, A. Deposição Estacional de serapilheira e macronutrientes em uma floresta de Araucária, São Mateus do Sul, Paraná. Revista do Instituto Florestal, v. 4, n. 3, p. 766-772, 1992.

BRAY, J.R. E GORHAM, E. Litter production in forest of the world. Advances in Ecological Research 2: 101-157. 1964 
BURGHOUTS, T. B. A.; CAMPBELL, E. J. F.; KODERMAN, R. J. Effects of tree species heterogeneity on leaf fall in primary an logged dipterocarp forest in the Ula Segana Forest Reserve. Sabah. Malasia. Jornal of Tropical Ecology . v10, p. 1-26. 1994.

BRUN, E. J.; SCHUMACHER, M. V.; VACCARO, S. \& SPATHELF, P. Relação entre a produção de serrapilheira e variáveis meteorológicas em três fases sucessionais de uma floresta estacional decidual no Rio Grande do Sul. Revista Brasileira de Agrometeorologia, v. 9, p.277-285, 2001

CARPANEZZI, A. A. Banco de sementes e deposição de folhedo e seus nutrientes em povoamentos de bracatinga (Mimosa scabrella Bentham) na Região Metropolitana de Curitiba-PR. 1997. 100 f. Tese (Doutorado) - Instituto de Biociências, Universidade Estadual Paulista, Rio Claro, 1997.

CESTARO, L.A. Estudo microclimático do interior de uma mata de araucária na Estação Ecológica de Aracuri, Esmeralda, RS. Revista Árvore. 12 (1): 4157. 1988.

CHABOT, B.F. E HICKS, D.J.. The ecology of leaf life span. Annual Rewiew of Ecology and Systematics. 13: 229-243.1982

CIANCIARUSO, M.V; PIRES, J.S.R;, WELINGTON BRÁZ CARVALHO DELITTI W.B.C; PEREIRADA SILVA, É. F. L. Produção de serapilheira e decomposição do material foliar em um cerradão na Estação Ecológica de Jataí, município de Luiz Antônio, SP, Brasil Acta bot. bras. 20: p.49-59. 2006.

CHANG, M. Y. Faxinais no Paraná. Informe de pesquisa, n. ${ }^{\circ}$ 80. Londrina: IAPAR, 1986.

CUNHA, G. C.; GRENDENE, L. A.; DURLO, M. A.; BRESSAN, D. A. Dinâmica nutricional em floresta estacional decidual com ênfase aos minerais provenientes da deposição da serapilheira. Ciência Florestal, Santa Maria, v.3, n.1, p.19-39, 1993.
COELHO NETTO, A. L. Hidrologia de encosta na interface com a geomorfologia. In: GUERRA, A. T.; CUNHA, S. B. (org.) Geomorfologia: uma atualização de bases e conceitos. 2. ed. Rio de Janeiro: Bertrand Brasil, 1995, p. 93-148.

DIAS, H.C.T.; OLIVEIRA FILHO, A.T. 1997. Variação temporal e espacial da produção de serrapilheira em uma área de floresta estacional semidecídua montana em Larvras-MG. Revista Árvore, 21: 11-26.

EMBRAPA. Sistema brasileiro de classificação de solos. Brasília: Embrapa, 1999. 412p.

FERNANDES, A.V. E BACKES, A. Produtividade primária em floresta com Araucaria angustifolia no Rio Grande do Sul. Iheringia, Série Botânica. 51(1): 63-78, 1998.

FIGUEIREDO FILHO, A. et al. Avaliação Estacional a Deposição de Serapilheira em uma Floresta Ombrófila Mista Localizada no Sul do Paraná. Ciência Florestal, v.13, n. 1, p. 11- 18, 2003.

GREACEN, E.L. e SANDS, R. Compaction of forest soils: A review. Aust. J. Soil Res., 18:163- 169, 1980.

GUERRA.A.J.T. Ravina: processo de formação e desenvolvimento. Anuário do Instituto de Geociências, UERJ. v 2, 80-95, 1998.

HARRIS, R.F.; CHESTERS, G.; ALLEN, O.N. Dinamics of soil agragation. Advencein Agronomy. $\mathrm{v}$ 18, 107- 169, 1966.

JARENKOW, J.A. e BAPTISTA, L.R.M. Composição florística e estrutura da mata com araucária na Estação Ecológica de Aracuri, Esmeralda, Rio Grande do Sul. Napaea. 3: 9-18. 1978

LANZANOVA, M.E. Atributos físicos do solo em sistemas de culturas sob plantio direto na integração lavoura-pecuária. Dissertação (Mestrado) Santa Maria, Universidade Federal de Santa Maria, 2005. 125p. 
LEITÃO FILHO, H. F., PAGANO, S. N., CESAR, O, TIMONI, J. L. \& RUEDA, J. J. Ecologia da Mata Atlântica em Cubatão (SP). Editora da UNESP, São Paulo- Editora da UNICAMP, Campinas. 1993.

MARTINS, S.V.e RODRIGUES,R.R. Produção de serapilheira em clareiras de uma floresta estacional semidecidual no município de Campinas, SP. Revista Brasileira de Botânica. São Paulo, V.22, n.3, p.405-412, dez. 1999 Revista Brasileira de Botânica vol.24 n.2 São Paulo 2001.

MAZUREC, A.P. E VILLELA, D.M. Produção e camada de serapilheira em uma Mata Atlântica na Serra do Imbé, norte fluminense, em diferentes altitudes. Pp. 36-42. In: Anais do IV Simpósio de Ecossistemas Brasileiros. v.3., Águas de Lindóia, São Paulo, ACIESP. 1998.

MITCHELL, H.H. \& TEEL, M.R. Winter annual cover crops for notillage corn production. Agron. J., Madison, 69:569-573, 1997.

PAGANO, S.N.. Produção de folhedo em mata mesófila semidecídua no município de Rio Claro, SP. Revista Brasileira de Biologia. 49:633-639. 1989

PEZZATTO A. W. E WISNIEWSKI, C. Produção de serapilheira em diferentes seres sucessionais da Floresta Estacional Semidecidual no Oeste do Paraná. Floresta. Curitiba, v. 36, n. 1, jan./abr. 2006.

PORTES, M.C.G.O; KOEHLER, A.; GALVÃO, F. Floresta ombrófila densa altomontana: avaliação da deposição de serapilheira e de nutrientes. In: CONGRESSO NACIONAL DE BOTÂNICA, 49., 1998, Salvador. Resumos. Instituto de Biologia, 1998. 302p.

RODRIGUES, M.P. Uso da infiltrabilidade como indicador de reabilitação de áreas de empréstimo. (Monografia apresentada para obtenção do titulo de Engenheiro Florestal), UFRRJ, Seropédica, 29 p, 2005.

SCHUMACHER, M.V.; BRUM, E., HERNANDES, J. L.; KÖNIG, F. G. Produção de Serrapilheira em
Floresta de Araucaria angistifolia (Bertol) Kuntze no Município de Pinhal Grande- RS. Revista Árvore, vol 28, nº p. 29-37. 2004.

SPAIN, A.V.; Litterfall and the Standing crop of litter in three Tropical Australian Rainforests. Journal of Ecology. v.72 p. 947-961. 1984.

SOUZA. R. M. Mapeamento Social dos Faxinais no Paraná. Instituto Equipe de Educadores Populares IEEP, Articulação Puxirão dos Povos Faxinalenses. 2007, 59 p.

SWANK, W.T.; GOEBEL, N.B. \& HELVEY, J.D. Interception loss in loblolly pine stands of the South Carolina Piedmont. Journal of Soil and Water Conservation. Ankeny, 27(4): 160-164. 1972.

THOMAZ, E. L. Dinâmica do uso da terra e degradação do solo na bacia do Rio Guabiroba - Guarapuava/ PR. RA'E GA, n. 13, p. 109-128, 2007.

THOMAZ, E. L.; DIAS, W. A. Bioerosão - evolução do rebanho bovino brasileiro e implicações nos processos geomorfológicos. Revista Brasileira de Geomorfologia, v. 10, n. 2, p. 3-11, 2009.

TREVISAN, G. V. Biomassa e produção de serapilheira no parque Estadual "Mata dos Godoy". Londrina, PR. Londrina, 24 f. Monografia (Graduação em Ciências Biológicas) - Centro de Ciências Biológicas, Universidade Estadual de Londrina, Londrina, 1998.

VOIGHT, V.P; WALSH, R.P.D. Hidrologische prozesse in bodenstreu. Einige experimentelle befunde. Schr. Naturw. Ver Schelesw. V.46. 35-45. 1976.

VOGT, K.A, GRIER, C. C.; VOGT, D.C. Production turnover and nutrient dynamics of above belowground detritus of word forest. Advaces in Ecological Research. v15. 1986.

WIDOWSKI, T. M. Shade-seeking behavior of rotationally-grazed cows and calves in a moderate climate. In: STOWELL, R. R., BUCKLIN, R.; BOTTCHER, R. W. In: INTERNATIONAL SYMPOSIUM, 6th., 
2001. Proceedings... Louisville, Kentucky, USA: ASABE, 2001.p. 632-639. Livestock Environment VI

WILDNER, L.P. Efeito da adição de diferentes residuos orgânicos nas perdas de solo e água em um solo Podzólico Vermelho-Amarelo. 1985. 100 f. Dissertação (Mestrado em Agronomia) - Universidade Federal de Santa Maria, Santa Maria, 1985.

THOMAZ, E. L.; ANTONELI; V. Avaliação de interceptação de chuva em fragmento Secundário de Floresta Ombrófila Mista (faxinal), Guarapuava PR. Ciência Florestal. 2011 (no prelo).

DICKOW, K. M. C.;MARQUES, R.; PINTO, C. B. Lixiviação de nutrientes da serapilheira recém depositada em sucessão ecológica na Floresta Atlântica, Litoral do Paraná. FLORESTA, Curitiba, v. 39, n. 1, p. 145-156, jan./mar. 2009. 